\title{
The prevalence of Helicobacter
} CrossMark pylori infection and other risk factors among Mongolian dyspeptic patients who have a high incidence and mortality rate of gastric cancer

Oyuntsetseg Khasag ${ }^{1 \dagger}$, Gantuya Boldbaatar ${ }^{1,2 \dagger}$, Tserentogtoh Tegshee ${ }^{1}$, Davaadorj Duger ${ }^{1}$, Azzaya Dashdorj ${ }^{2}$, Tomohisa Uchida ${ }^{3}$, Takeshi Matsuhisa ${ }^{4}$ and Yoshio Yamaoka ${ }^{2,5^{*}}$

\begin{abstract}
Background: Mongolia has not only the second highest incidence rate but also the highest mortality rate for gastric cancer globally. In addition to gastric cancer, ulcerative disease complications are also life threatening; thus, investigating Helicobacter pylori infection and other risk factors is essential.

Results: H.pylori infection was high in tested dyspeptic patients from all parts of Mongolia, with an overall infection rate of $80.0 \%$. Logistic regression analysis showed that $H$. pylori infection was associated with gastritis (odds ratio; 9.0 ([95\% confidence interval 5.0-16.2]); $p<0.0001)$. H. pylori infection (3.3 [2.0-5.4]; $p<0.0001)$ and $>40$ years old (1.5 $[1.0-2.0] ; p<0.02)$ were both associated with atrophy. However, $>40$ years old (3.8 [2.4-6.0]; $p<0.0001)$ and high salt intakes (1.6 [1.0-2.3]; $p<0.02$ ), but not H. pylori infection, were associated with intestinal metaplasia. Excessive amount of salt usage was dramatically higher in northern and western parts of Mongolia, where precancerous diseases, such as erosive esophagitis (for cardia cancer), severe atrophy, and intestinal metaplasia (for non-cardia cancer), were highly prevalent.
\end{abstract}

Conclusions: H. pylori infection was the major gastric health problem among the Mongolian population. In addition, environmental factors such as high salt intake worsened the clinical outcome. Therefore, a nationwide screening and eradication of $H$. pylori infection as well as salt-reducing measures should be implemented.

Keywords: Helicobacter pylori, Risk factors, Gastric diseases, Mongolia

\section{Background}

Mongolia has the second highest incidence of gastric cancer (GC) worldwide [1]. According to the national health indicator data, digestive system diseases are the second most common disease among the Mongolian

\footnotetext{
*Correspondence: yyamaoka@oita-u.ac.jp

${ }^{\dagger}$ Khasag Oyuntsetseg and Boldbaatar Gantuya contributed equally to this work

${ }^{2}$ Department of Environmental and Preventive Medicine, Oita University Faculty of Medicine, 1-1 Idaigaoka, Hasama-machi, Yufu, Oita 879-5593, Japan

Full list of author information is available at the end of the article
}

population [2]. Moreover, ulcerative disease complications such as bleeding and perforation are severe and life threatening $[3,4]$. In 1994, Helicobacter pylori was declared to be a class I carcinogen [5, 6]. Currently, it is well known as the main etiological factor for chronic gastritis, peptic ulcer disease (PUD), mucosa-associated lymphoid tissue (MALT) lymphoma and GC [7, 8]. In addition, the infection was also reported as a risk factor for gastric dyspepsia in the Maastricht $\mathrm{V}$ guideline [9]. H. pylori is a flagellated, spiral-shaped, Gram-negative, microaerophilic bacteria which can survive in acidic environment and colonizes the gastric mucosa in half of 
the world population [10]. A current global systematic review showed that $H$. pylori infection continues to be a major public health issue worldwide, and approximately 4.4 billion individuals were estimated to be infected [10]. The prevalence of $H$. pylori infection varies geographically, based on ethnicity, age, socioeconomic factors, and is more frequent in developing than developed countries [11]. It has been attributed to low socioeconomic status, overcrowded condition, and inadequate hygiene [12, 13]. The infection is usually acquired in early childhood and reaches $80-100 \%$ during adolescence in developing countries [8] probably due to oral-oral, fecal-oral [14], or gastro-oral transmission [15].

Mongolia is a landlocked country in Central East Asia, bordered by the Russian Federation in the north and People's Republic of China in the south, west, and east. According to the age-standardized rate (ASR) of GC per 100,000 Mongolian population, Uvs Province (western part of Mongolia) has the highest (80.7) and Khentii Province (eastern part of Mongolia) has the lowest (11.2) incidence, with the country average of 32.4 , which was ranked as the second highest globally [1].

The precancerous diseases of GC and its etiological risk factors including $H$. pylori infection are not well studied based on geographical location. In addition to high incidence and mortality rates of GC, digestive diseases have been constantly increasing in the last 10 years in Mongolia [2]. In this serious situation, defining etiologies of these diseases is urgently required, especially in areas with high incidence of GC. Therefore, this study aimed to examine the prevalence of $H$. pylori infection and other risk factors among dyspeptic patients in the major geographical locations (western, northern, southern, and central parts) in Mongolia.

\section{Methods}

\section{Sampling, questionnaire and endoscopy of patients}

We conducted a cross-sectional study among dyspeptic patients aged $>16$ years, from 2014 to 2016. History of partial or total gastrectomy; treatment with bismuthcontaining compounds, $\mathrm{H} 2$-receptor blockers, or proton pump inhibitors within 2 weeks prior to the start of the study and history of previous eradication therapy for $H$. pylori infection were the exclusion criteria.

We chose the places according to the geographical location and GC incidence rate in the 2012 Mongolian national data. The selected places were as follows: Ulaanbaatar City (central part of Mongolia, with an ASR of GC incidence of 31.3 per 100,000 population), Uvs Province (western; ASR, 80.7), Khuvsgul Province (northern; ASR, 37.0), Umnugovi Province (northern; ASR, 21.5), and Khentii Province (eastern; ASR, 11.5).
Age and gender were used as non-modifiable risk factors, and high salt intake and bad habits (tobacco smoking and alcohol drinking) were used as modifiable environmental risk factors. A previous nationwide study validated the questionnaire method by evaluating the excessive amount of salt using $24 \mathrm{~h}$ urine collection samples, revealing that the urine saline level was higher in daily salty tea drinkers than those who drink from other sources [16]. Therefore, to determine excessive amount of salt, we used the same questionnaire method to screen routine salty tea drinkers. For bad habits, tobacco smoking (daily smokers) and alcohol drinking (excessive amount of standard drink [350 mL glass of beer, $150 \mathrm{~mL}$ glass of $12 \%$ wine, or $44 \mathrm{~mL}$ glass of spirit] per monthly, weekly, or daily) statuses were used.

During endoscopic examination, the Los Angeles (LA) classification was used to determine gastroesophageal reflux disease [17]. Gastric mucosal atrophy was evaluated using the Kimura-Takemoto classification [18] and was classified as closed type (mild atrophy, limited in the antrum and lesser curvature of the proximal corpus) and open type (advanced atrophy, extended into the corpus and cardia). Three gastric mucosal tissues were taken from the antrum approximately $3 \mathrm{~cm}$ from the pyloric ring, which were used for rapid urease test (Mon-HP, developed at the Mongolian National University of Medical sciences, Ulaanbaatar, Mongolia), histological examination, and bacterial culture. Two more biopsies were taken from the corpus and incisura angularis (angulus) for histological examination. If ulcer or suspected cancer lesions were detected, additional biopsy specimen(s) was taken for histological diagnosis. Biopsy specimens for culture were immediately placed at $-20^{\circ} \mathrm{C}$ on the day of endoscopic examination and stored at $-80{ }^{\circ} \mathrm{C}$ until used for culture testing. Blood samples from all participants were collected on the same day. The serum was separated and frozen at $-80{ }^{\circ} \mathrm{C}$ until analysis. Written informed consent was obtained from all participants, and the ethical permission was approved by the Mongolian Ministry of Health, Mongolian National University of Medical Sciences, and Oita University Faculty of Medicine (Yufu, Japan).

\section{Histological confirmation}

All biopsy materials were fixed in $10 \%$ buffered formalin and embedded in paraffin. Serial sections were stained with hematoxylin-eosin and May-Giemsa stain. The stained slides were examined by a single pathologist (Tomohisa Uchida). The degree of chronic inflammation (mononuclear cell infiltration), acute inflammation (polymorphonuclear neutrophil infiltration), atrophy, intestinal metaplasia (IM), and bacterial density were classified 
into four grades, based on the updated Sydney system: 0, "normal"; 1, "mild"; 2, "moderate"; and 3, "marked" [19]. Samples with grade 1 or higher were considered positive.

\section{Helicobacter pylori infection status}

H. pylori infection was positive based on culture or histology, confirmed by immunohistochemistry (IHC) or both rapid urease test (RUT) and serology that yielded positive results. For $H$. pylori culture, antral biopsy specimen was homogenized in normal saline solution and placed in a commercially available selective plate (Nissui Pharmaceutical Co. Ltd, Japan). The plates were incubated for up to 10 days at $37{ }^{\circ} \mathrm{C}$ under microaerophilic conditions $\left(10 \% \mathrm{O}_{2}, 5 \% \mathrm{CO}_{2}\right.$, and $\left.85 \% \mathrm{~N}_{2}\right)$. H. pylori were identified based on colony morphology, Gram staining, and positive reactions for oxidase, catalase, and urease tests.

In histological examination, bacterial loads $\geq$ grade 1 on the updated Sydney system were considered positive for $H$. pylori [19]. IHC was also performed to confirm $H$. pylori infection as previously described [20]. Serology of $H$. pylori infection (anti-H. pylori IgG antibody) was evaluated using a commercially available ELISA kit (Eiken Co., Ltd., Tokyo, Japan) according to the manufacturer's instructions.

\section{Statistical analysis}

Discrete categorical variables were tested using Chi square test, and non-parametric continuous variables were calculated using Mann-Whitney test or KruskalWallis test. A two-tailed $p$ value of $<0.05$ was considered statistically significant. Univariate and backward logistic regression analyses were used to calculate odds ratios. In the univariate analysis, $p<0.3$ was included to calculate the multivariate backward logistic regression analysis. All statistical analyses were performed using IBM SPSS Version 22.0 (IBM Corp. Armonk, NY, USA) software.

\section{Results}

\section{Patient sampling and demography}

Endoscopy was performed on 905 dyspeptic patients from the capital city (Ulaanbaatar, $\mathrm{n}=226$; November $18-22,2014$ ), western (Uvs Province, $n=148$; July $14-21$, 2015), northern (Khuvsgul Province, $\mathrm{n}=212$; July 19-25, 2015), southern (Umnugovi Province, $\mathrm{n}=176$; August $4-8,2016$ ), and eastern (Khentii Province, $n=143$; August 9-12, 2016) parts of Mongolia. All patients were examined by experienced Japanese and Mongolian endoscopists. A total of 169 patients were excluded from the study due to our exclusion criteria that patients were previously received $H$. pylori eradication. Finally, we included 736 dyspeptic patients. Among all patients, $68.2 \%(502 / 736)$ were females and $31.8 \%$ (234/736) were males, with the mean age $\pm S D$ of $43.6 \pm 13.6$ years, ranging from 15 to 87 years: $18.5 \%$ aged $\leq 30$ years; $20.8 \%$, $30-39$ years; $24.9 \%, 40-49$ years; $23.4 \%, 50-59$ years; and $12.5 \%, \geq 60$ years. About $88.7 \%$ (653/736) belong to the major (Khalkh) and 11.3\% (83/736) to the minor (nonKhalkh) ethnicity groups. The minor ethnicities were Bayad (44.6\%, $\mathrm{n}=37)$, Durvud $(42.2 \%, \mathrm{n}=35)$, Khoton $(7.2 \%, \mathrm{n}=6)$, Tuva $(2.4 \%, \mathrm{n}=2)$, Darkhad $(1.2 \%, \mathrm{n}=1)$, Khotgoid $(1.2 \%, \mathrm{n}=1)$, and Myangad $(1.2 \%, \mathrm{n}=1)$.

\section{Demographic and disease backgrounds by geographical location}

Table 1 shows the demographic and endoscopic diagnosis based on geographical locations. Age and gender were not different based on the location, but ethnic groups were different. Most patients (66.7\%) belonged to the minor ethnic (Bayad, Durvud, and Khoton) groups in the western part (Uvs Province) $(p<0.0001)$, whereas almost all patients in other locations belonged to the major (Khalkh) group. Northern and western parts had a significantly higher incidence of reflux esophagitis (LA grades, A-D) and atrophic gastritis (open type) compared with other regions. The prevalence of gastric and duodenal ulcer did not differ by location (Table 1). Endoscopic and histological diagnosis was not significantly different by ethnic group.

\section{Helicobacter pylori infection rate by demography}

Table 2 shows the different diagnostic tests for $H$. pylori infection based on age group, gender, and geographical locations of all dyspeptic patients. Based on our criteria (positive by culture or histology, or positive for both RUT and serology), the prevalence of current $H$. pylori infection was $80.0 \%$ (589/736), with $5.2 \%$ (38/736) being positive by serology only and therefore were regarded as the cases with past infection. The remaining $14.8 \%$ $(109 / 736)$ were regarded as the uninfected group. Based on gender, the prevalence of current infection was not significantly different from $78.2 \%(183 / 234)$ in men and $80.9 \%(406 / 502)$ in women. The infection rate based on age group was $83.8 \%$ for patients $<30$ years, $88.2 \%$ for $30-39$ years, $81.4 \%$ for $40-49$ years, $74.4 \%$ for $50-59$ years, and $68.5 \%$ for $\geq 60$ years. H. pylori infection peaked in patients aged 30-39 years, but was lower in older patients $(p=0.005)$.

The infection rate based on geographical locations was highest in Umnugovi (87.1\%; 108/124), followed by Khentii $(87 \% ; 100 / 115)$, Khuvsgul $(78.4 \% ; 134 / 171)$, and Uvs (77.5\%; 93/120) provinces and Ulaanbaatar city $(74.8 \%$; $154 / 206)(p=0.03)$. The prevalence of $H$. pylori was not different based on ethnic groups: $80.1 \%(523 / 653)$ in the major and $79.5 \%(66 / 83)$ in the minor ethnic groups $(p=0.5)$. 
Table 1 Demography and diseases according to geography

\begin{tabular}{|c|c|c|c|c|c|c|}
\hline \multirow[t]{2}{*}{ Parameters } & \multicolumn{6}{|c|}{ Geographical location } \\
\hline & $\begin{array}{l}\text { Eastern } \\
\text { (Khentii) }\end{array}$ & $\begin{array}{l}\text { Southern } \\
\text { (Umnugovi) }\end{array}$ & $\begin{array}{l}\text { Central } \\
\text { Ulaanbaatar city }\end{array}$ & $\begin{array}{l}\text { Northern } \\
\text { (Khuvsgul) }\end{array}$ & $\begin{array}{l}\text { Western } \\
\text { (Uvs) }\end{array}$ & $p$ value \\
\hline Number of cases & $n=115$ & $n=124$ & $n=206$ & $n=171$ & $n=120$ & \\
\hline Mean age with SD & $47.4 \pm 12.6$ & $44.3 \pm 13.8$ & $41.5 \pm 15.4$ & $43.5 \pm 12.7$ & $42.6 \pm 11.9$ & NS \\
\hline Age range & $17-87$ & $15-79$ & $17-79$ & 19-75 & $16-74$ & NS \\
\hline \multicolumn{7}{|l|}{ Gender } \\
\hline Female & $73 \%$ & $71 \%$ & $65.5 \%$ & $65.5 \%$ & $69.2 \%$ & NS \\
\hline Male & $27 \%$ & $29 \%$ & $34.5 \%$ & $34.5 \%$ & $30.8 \%$ & NS \\
\hline \multicolumn{7}{|l|}{ Ethnicity } \\
\hline Major & $97.8 \%$ & $100 \%$ & $N / A^{a}$ & $98.4 \%$ & $33.3 \%$ & 0.0001 \\
\hline Minor & $2.2 \%$ & $0 \%$ & & $1.6 \%$ & $66.7 \%$ & \\
\hline \multicolumn{7}{|l|}{ Endoscopy diagnosis } \\
\hline Gastric ulcer & $3.5 \%$ & $3 \%$ & $2.4 \%$ & $2.9 \%$ & $2.5 \%$ & NS \\
\hline Duodenal ulcer & $0 \%$ & $0.8 \%$ & $1.9 \%$ & $1.8 \%$ & $1.7 \%$ & NS \\
\hline Erosive GERD & $5.2 \%$ & $9.7 \%$ & $5.3 \%$ & $11.7 \%$ & $14.2 \%$ & 0.03 \\
\hline Open type atrophy & $1.3 \%$ & $1.8 \%$ & $1.4 \%$ & $6.0 \%$ & $13 \%$ & 0.0001 \\
\hline \multicolumn{7}{|l|}{ Histology diagnosis } \\
\hline Intestinal metaplasia & $19.1 \%$ & $21.8 \%$ & $16 \%$ & $23.4 \%$ & $32.5 \%$ & 0.01 \\
\hline
\end{tabular}

a We could not obtain data

Table $2 H$. pylori infection by different tests and overall infection status

\begin{tabular}{|c|c|c|c|c|c|c|c|c|c|c|}
\hline \multirow[t]{2}{*}{ Parameters } & \multicolumn{6}{|c|}{ H. pylori different tests } & \multicolumn{3}{|c|}{ H. pylori diagnosis } & \multirow[t]{2}{*}{$p$ value } \\
\hline & $\mathbf{N}$ & RUT (\%) & Culture (\%) & Histology (\%) & IHC (\%) & Serology (\%) & Current (\%) & Past (\%) & Uninfected (\%) & \\
\hline Overall & 736 & 67.3 & 48.2 & 75.8 & 76.0 & 64.3 & 80.0 & 5.2 & 14.8 & \\
\hline \multicolumn{11}{|l|}{ Age group } \\
\hline$<30$ & 136 & 73.5 & 55.1 & 79.4 & 79.4 & 69.9 & 83.8 & 3.7 & 12.5 & \multirow[t]{5}{*}{0.005} \\
\hline $30-39$ & 153 & 79.7 & 52.3 & 83.7 & 83.7 & 75.2 & 88.2 & 5.2 & 6.6 & \\
\hline $40-49$ & 183 & 62.8 & 43.2 & 76.0 & 76.5 & 59.0 & 81.4 & 4.9 & 13.7 & \\
\hline $50-59$ & 172 & 61.6 & 45.3 & 70.3 & 70.3 & 62.2 & 74.4 & 5.2 & 20.3 & \\
\hline$<60$ & 92 & 56.5 & 46.7 & 67.4 & 67.4 & 52.2 & 68.5 & 7.6 & 23.9 & \\
\hline \multicolumn{11}{|l|}{ Gender } \\
\hline Female & 502 & 67.9 & 51.0 & 77.1 & 77.1 & 66.9 & 80.9 & 5.0 & 14.1 & \multirow[t]{2}{*}{ NS } \\
\hline Male & 234 & 65.8 & 42.3 & 73.1 & 73.5 & 58.5 & 78.2 & 5.6 & 16.2 & \\
\hline \multicolumn{11}{|l|}{ Place } \\
\hline Umnugovi & 124 & 68.5 & 63.7 & 83.9 & 83.9 & 70.2 & 87.1 & 1.6 & 11.3 & \multirow[t]{5}{*}{0.03} \\
\hline Khentii & 115 & 68.7 & 80.0 & 80.9 & 80.9 & 72.2 & 87.0 & 4.3 & 8.7 & \\
\hline Khuvsgul & 171 & 62.6 & 19.3 & 74.9 & 74.9 & 63.7 & 78.4 & 8.2 & 13.5 & \\
\hline Ulaanbaatar & 206 & 67.0 & 63.6 & 71.8 & 72.3 & 58.7 & 74.8 & 5.3 & 19.9 & \\
\hline Uvs & 120 & 71.7 & 16.7 & 70.8 & 70.8 & 60.8 & 77.5 & 5.0 & 17.5 & \\
\hline
\end{tabular}

$R U T$ rapid urease test, $I H C$ immunohistochemistry

Histological diagnosis based on $\mathrm{H}$. pylori infection

Figure 1 shows the histological diagnosis based on the updated Sydney system by $H$. pylori infection. Acute (neutrophil) and chronic inflammation (monocyte) scores were significantly higher in patients with current
H. pylori infection compared to those with past infection and those who were uninfected based on each biopsy site (the antrum, angulus, and corpus). Acute and chronic inflammation scores were also significantly higher in those with past infection than in the uninfected group in 


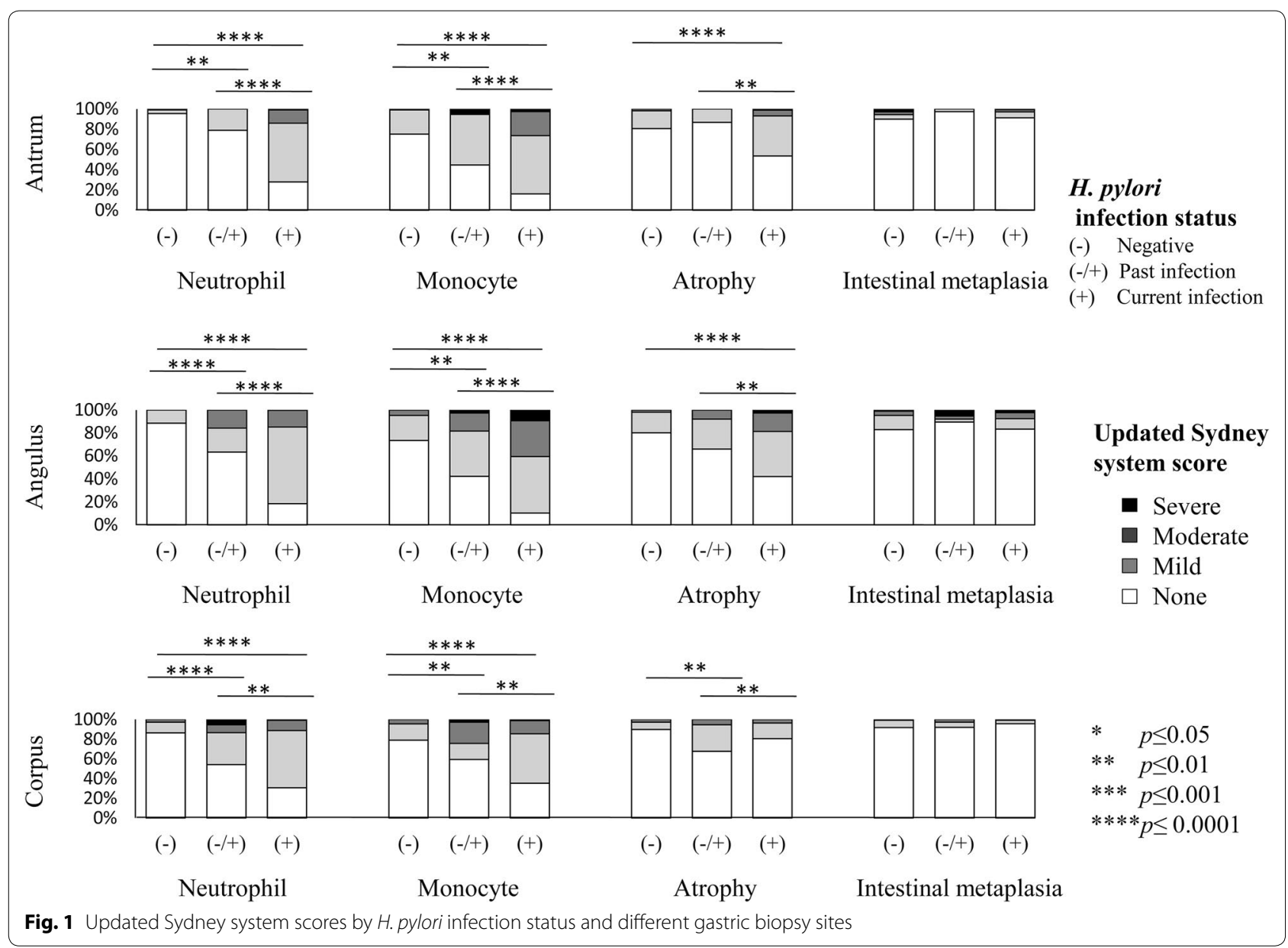

each biopsy site. The atrophy score was also significantly higher in patients with current infection status than those with negative and past infection status in the antrum and angulus. The corpus atrophy scores were higher in the past infection group than in the current and uninfected groups. Interestingly, IM scores in all sites were independent of $H$. pylori infection (Fig. 1).

\section{Helicobacter pylori infection rate by endoscopy and histological diagnosis}

Figure 2 shows the $H$. pylori infection rate according to endoscopic diagnoses. On esophageal endoscopy, 63.6\% $(42 / 66)$ of overall erosive esophagitis (LA grade, A-D) patients were infected with $H$. pylori; in the stomach, $90.5 \%(19 / 21)$ of gastric ulcer and $76.9 \%(20 / 26)$ of open type atrophy; and in the duodenum, 100\% (10/10) of duodenal ulcer patients were infected with $H$. pylori.

Next, we summarized $H$. pylori infection status based on the overall histological diagnosis as "yes" or "no" status for the following groups: normal "yes" status, all scores in three sites were $0(\mathrm{n}=57)$; gastritis "yes" status, neutrophil or monocyte scores were $1-3$ in at least

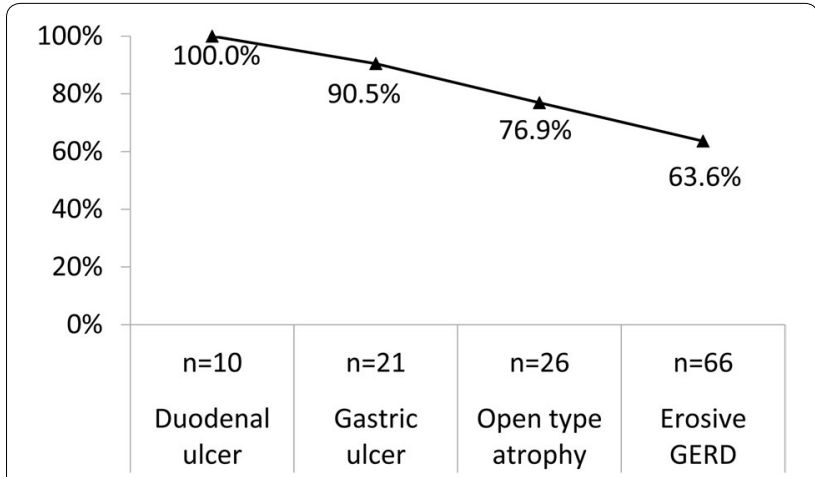

Fig. 2 The prevalence of H. pylori infection by endoscopic diagnoses

one site ( $\mathrm{n}=659)$; atrophy "yes" status, atrophy score was $1-3$ in at least one site $(\mathrm{n}=483)$; and IM "yes" status, IM score was $1-3$ in at least one site $(n=160)$ (Table 3$)$.

As expected, the prevalence of $H$. pylori infection was significantly lower in the normal group $(p<0.0001)$, but significantly higher in the gastritis $(p<0.0001)$ and 
Table 3 H. pylori infection status according to histological diagnosis

\begin{tabular}{|c|c|c|c|c|c|}
\hline Parameters & Case number & Current infection (\%) & Past infection (\%) & Uninfected (\%) & $p$ value \\
\hline \multicolumn{6}{|c|}{ Histological diagnosis } \\
\hline \multicolumn{6}{|c|}{ Normal } \\
\hline No & 679 & 85.6 & 4.4 & 10.0 & \multirow[t]{2}{*}{0.0001} \\
\hline Yes & 57 & 14.0 & 14.0 & 72 & \\
\hline \multicolumn{6}{|l|}{ Gastritis } \\
\hline No & 77 & 11.7 & 11.7 & 76.6 & \multirow[t]{2}{*}{0.0001} \\
\hline Yes & 659 & 88.0 & 4.4 & 7.6 & \\
\hline \multicolumn{6}{|l|}{ Atrophy } \\
\hline No & 253 & 63.2 & 8.3 & 28.5 & \multirow[t]{2}{*}{0.0001} \\
\hline Yes & 483 & 88.8 & 3.5 & 7.7 & \\
\hline \multicolumn{6}{|l|}{ IM } \\
\hline No & 576 & 79.9 & 5.7 & 14.4 & \multirow[t]{2}{*}{ NS } \\
\hline Yes & 160 & 80.6 & 3.1 & 16.3 & \\
\hline
\end{tabular}

IM intestinal metaplasia

atrophy $(p<0.0001)$ groups. Importantly, the presence of IM was independent of $H$. pylori infection.

\section{Helicobacter pylori infection and other risk factors in high-risk diseases for GC}

Since IM was diagnosed among uninfected groups with gastritis, environmental factors were investigated in detail. Figure 3 shows the prevalence of $H$. pylori infection and other environmental factors by geographical location. Kruskal-Wallis test showed excessive amount of salt usage and alcohol drinking status were significantly higher in western and northern parts of Mongolia (Fig. 3).
Next, we evaluated these factors according to the highrisk disease group (erosive GERD for cardia GC and atrophy and IM for non-cardia GC). Table 4 shows the univariate and multivariate analysis results.

Multivariate logistic regression analysis showed that $H$. pylori infection was associated with increased risk for corpus gastritis (odds ratio, 54.0 [95\% confidence interval 25.8-113.2]); $p<0.0001)$. H. pylori infection was associated with increased risk for atrophy and decreased risk for erosive GERD. Our finding supports the consensus that $H$. pylori infection is a protective factor against GERD [21]. Age $>40$ years, male gender, and excessive amount of salt intake increased the risk of erosive GERD,

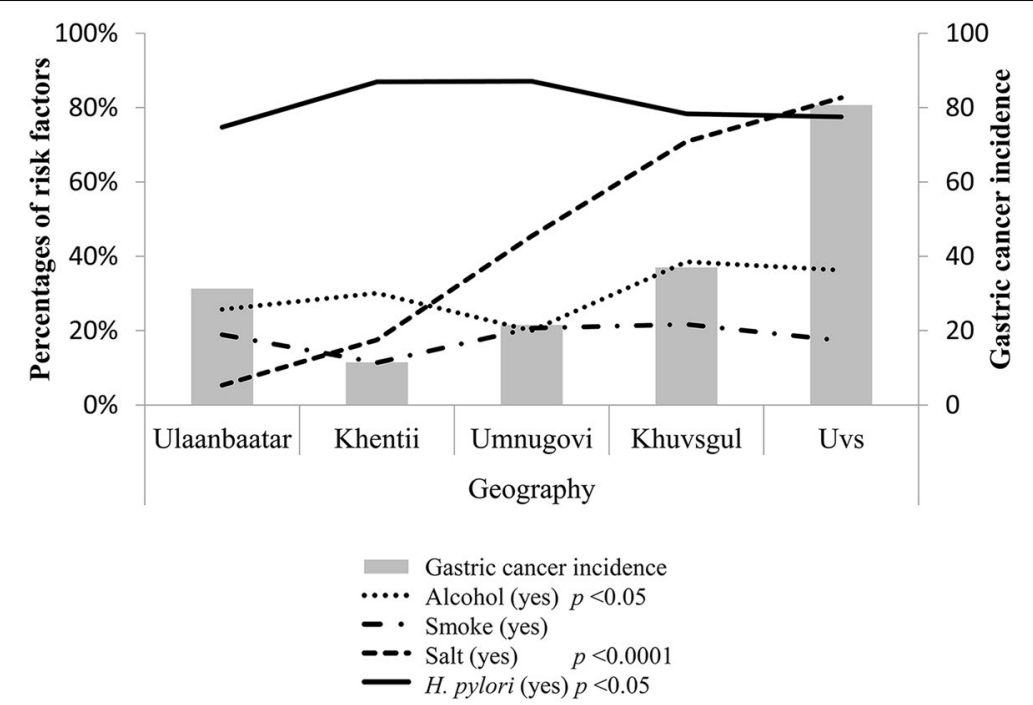

Fig. 3 The prevalence of H. pylori infection and other environmental factors by geographical location 
Table $4 \mathrm{H}$. pylori infection and other risk factor status according to high-risk diseases for GC

\begin{tabular}{|c|c|c|c|c|c|c|}
\hline \multirow[t]{2}{*}{ Parameters } & \multicolumn{2}{|c|}{ Erosive GERD } & \multicolumn{2}{|l|}{ Atrophy } & \multicolumn{2}{|c|}{ Intestinal metaplasia } \\
\hline & $p$ value & OR $(95 \% \mathrm{Cl})$ & $p$ value & OR $(95 \% \mathrm{Cl})$ & $p$ value & OR $(95 \% \mathrm{Cl})$ \\
\hline \multicolumn{7}{|l|}{ Univariate } \\
\hline H. pylori (yes) & 0.0001 & $0.4(0.2-0.6)$ & 0.0001 & $4.6(3.1-6.7)$ & 0.6 & $0.9(0.5-1.4)$ \\
\hline Age group (>40) & 0.002 & $2.3(1.4-4.8)$ & 0.9 & $1.0(0.7-1.4)$ & 0.0001 & $3.4(2.2-5.2)$ \\
\hline Gender (male) & 0.0001 & $3.5(2.1-5.9)$ & 0.4 & $0.8(0.6-1.2)$ & 0.04 & $1.5(1.0-2.1)$ \\
\hline Salt (yes) & 0.01 & $1.9(1.1-3.3)$ & 0.1 & $0.6(0.4-0.8)$ & 0.06 & $1.4(1.0-2.0)$ \\
\hline Smoke (yes) & 0.02 & $2.0(1.1-3.6)$ & 0.6 & $1.1(0.7-1.6)$ & 0.1 & $1.4(0.9-2.2)$ \\
\hline Alcohol (yes) & 0.5 & $1.2(0.7-2.0)$ & 0.6 & $1.0(0.7-1.5)$ & 0.1 & $1.3(0.9-2.0)$ \\
\hline \multicolumn{7}{|l|}{ Multivariate } \\
\hline H. pylori (yes) & 0.004 & $0.4(0.2-0.7)$ & 0.0001 & $5.1(3.5-7.7)$ & - & \\
\hline Age group (>40) & 0.002 & $2.9(1.4-5.6)$ & - & & 0.0001 & $3.8(2.4-5.9)$ \\
\hline Gender (male) & 0.0001 & $3.3(1.9-5.8)$ & - & & - & \\
\hline Salt (yes) & 0.007 & $2.1(1.2-3.7)$ & - & & 0.04 & $1.5(1.0-2.2)$ \\
\hline Smoke (yes) & - & & - & & - & \\
\hline Alcohol (yes) & - & & - & & - & \\
\hline
\end{tabular}

OR $(95 \% \mathrm{Cl})$ odds ratio (95\% confidence interval)

and age $>40$ years $(3.8[2.4-5.9] ; p<0.0001)$ and excessive salt intake $(1.5[1.0-2.2] ; p<0.02)$ increased the risk of IM.

\section{Discussion}

Mongolia is known for the highest mortality from GC in the world [1] and upper digestive tracts diseases are common [2]. Therefore we characterized features of gastric precancerous diseases and ulcerative diseases as well as demonstrating its risk factors among the Mongolian population. Gastric atrophy and IM are considered as the precursor disease for non-cardia GC [21] while GERD is considered as precursor disease for cardia GC [22]. We found that all these precursor diseases were higher in western followed by northern, southern, central and eastern part of Mongolia whereas ulcerative diseases were not significantly different by geographical location.

$H$. pylori infection is the major etiological factor that causes atrophic gastritis and development of IM is considered the most important recognizable risk factors for GC [21]. We found that $H$. pylori infection was associated with precursor GC diseases and ulcerative diseases among Mongolian patients. Most patients with atrophy and IM were infected with $H$. pylori (Table 3 ). For PUD, it was similar with other studies that approximately $90 \%$ of duodenal ulcer and $80 \%$ of gastric ulcer were associated with $H$. pylori infection [23]. PUD and GC can lead to fatal conditions, such as severe massive hemorrhage, perforation, and peritonitis [24]. For precancerous disease, multivariate analysis showed that $H$. pylori infection was associated with gastritis and atrophy (Table 4). Permanent $H$. pylori infection can cause chronic active gastritis, resulting in loss of glands (atrophy) and then development of IM [25]. H. pylori infection causes nearly $90 \%$ of non-cardia GC, and the most GC incidences were high in East Asian countries [1]. In China, Japan, and Korea, prospective studies confirmed that $H$. pylori infection played a major role in the occurrence of gastric atrophy and IM, which are the precancerous conditions, especially for non-cardia GC [26-28]. Indirect evidence from populations with a very low prevalence of $H$. pylori, such as the Malays of north eastern Peninsular Malaysia, is consistent with the idea that $H$. pylori decreased the risk of developing pre-neoplastic lesions and GC [29]. Since $H$. pylori infection is treatable, a $30-40 \%$ reduction in the incidence of GC was observed among treated subjects [30], and the cure of $H$. pylori infection reduced the precancerous disease progression to GC [31]. Therefore, $H$. pylori infection should be treated to reduce GC incidence among the Mongolian population. A previous study reported that $H$. pylori infection in adults mainly occurred before 15 years old [32]. Our study showed that the peak age of $H$. pylori infection was 30-39 years, while it was lower in older age (Table 2). Oral-oral and fecal-oral routes were considered as the crucial routes of $H$. pylori infection transmission [33]. Further risk factor studies are required to determine the transmission routes. The prevalence of $H$. pylori infection was generally high in Mongolia and did not differ by geographical location.

Interestingly, in spite of $H$. pylori infection, excessive amount of salt intake was dramatically higher in the northern and western parts of Mongolia, where precancerous diseases, such as erosive esophagitis (for cardia 
cancer), severe atrophy, and IM (for non-cardia cancer), were highly prevalent (Table 1 ). These results were consisted with the GC incidence (Fig. 3). H. pylori infection together with high salt intake has been reported to induce more gastric damage, such as atrophy and IM [34]. Furthermore, a prospective study confirmed that even salt alone could induce gastric atrophy and IM [35]. High salt intake causes damage to the gastric epithelium, followed by rapid restoration [36] and cell replication [37, 38]. Salting of foods increases the mutagenicity of nitrosated foods [39], and salt has been experimentally proven to increase the permeability of the experimental rat's gastric mucosa to carcinogenic agents $[40,41]$. H. pylorirelated gastric atrophy is considered as the major precursor disease for IM [42]; however, IM may also develop because of other harmful environmental factors, because of its gastric tissue repairing process [43, 44]. Our study showed that excessive amount of salt intake and advanced age ( $>40)$ increased the risk of IM (Table 4$)$. Moreover, salt, advanced age, and male gender increased the risk of GERD. Some previous studies have found that increased salt consumption was associated with GERD, which was attributed to the delayed gastric emptying and increased pancreaticobiliary secretion after high salt intake $[45,46]$. H. pylori infection, especially with a strain bearing CagA, is commonly considered a protective factor against GERD [47]. Our study results are consistent with the concept that $H$. pylori reduced the risk of erosive GERD. Excessive amount of salt intake seemed to play a major role for esophageal and gastric diseases, especially in western and northern parts of Mongolia. Further prospective studies are required to determine the pathogenesis of these diseases.

\section{Conclusions}

Based on our current result, we concluded that $H$. pylori infection is a major health problem for stomach diseases, such as PUD and atrophic gastritis among the Mongolian population. Nationwide screening and eradication of $H$. pylori infection are required. In addition, managing modifiable risk factors such as reducing excessive amount of salt intake and bad habits might help in decreasing erosive GERD and IM.

\section{Authors' contributions}

$\mathrm{OK}, \mathrm{GB}$ and $\mathrm{YY}$ conceived and designed the study; OK, GB, TT, DD, AD, TM and $Y Y$ contributed by collecting samples; GB, $A D$ and TU performed the experiments; $G B$ and $Y Y$ contributed to analysis and interpretation; $O K, G B$ and $Y Y$ drafted the manuscript. All authors read and approved the final manuscript.

\footnotetext{
Author details

${ }^{1}$ Mongolian National University of Medical Sciences, Ulaanbaatar, Mongolia.

2 Department of Environmental and Preventive Medicine, Oita University Faculty of Medicine, 1-1 Idaigaoka, Hasama-machi, Yufu, Oita 879-5593, Japan.

${ }^{3}$ Department of Molecular Pathology, Oita University of Medicine, Yufu, Japan.

${ }^{4}$ Department of Gastroenterology, Tama-Nagayama University Hospital,
}

Nippon Medical School, Tokyo, Japan. ${ }^{5}$ Department of Gastroenterology and Hepatology, Baylor College of Medicine and Michael De Bakey Veterans Affairs Medical Center, Houston, TX 77030, USA.

\section{Acknowledgements}

We wish to thank Adiyasuren Battulga, Namdag Bira, Tsogt-Ochir Byambajav, Otgondemberel Bolor and Batsuren Bilguudei for collecting samples.

\section{Competing interests}

The authors declare that they have no competing interests.

\section{Availability of data and materials}

All data and material will be available upon requests to the corresponding author.

\section{Consent for publication}

Not applicable.

\section{Ethics approval and consent to participate}

Ethical approval was obtained from the Ethics Committees of Ministry of Health, Mongolian National University of Medical Sciences, Ulaanbaatar, Mongolia and Oita University Faculty of Medicine, Japan. All participants signed written informed consent in this study.

\section{Funding}

This work was supported by Grants-in-Aid for Scientific Research from the Ministry of Education, Culture, Sports, Science and Technology (MEXT) of Japan (26640114, $15 \mathrm{H} 02657$ and 16H05191) (Y.Y.), the Special Coordination Funds for Promoting Science and Technology from the MEXT of Japan (Y.Y.), and National Institutes of Health Grants DK62813 (Y.Y.). GB and AD are doctoral students supported by the Japanese Government (Monbukagakusho: MEXT) Scholarship Program for 2014 and 2016.

\section{Publisher's Note}

Springer Nature remains neutral with regard to jurisdictional claims in published maps and institutional affiliations.

Received: 26 January 2018 Accepted: 23 March 2018

Published online: 04 April 2018

\section{References}

1. http://globocan.iarc.fr/. Accessed 17 Apr 2015.

2. Ch.Bat-Erdene. Mongolian Health Indicators 2012. Center for Health Development, 2013.

3. Bertleff MJ, Lange JF. Perforated peptic ulcer disease: a review of history and treatment. Dig Surg. 2010;27(3):161-9.

4. Thorsen K, Glomsaker TB, von Meer A, Søreide K, Søreide JA. Trends in diagnosis and surgical management of patients with perforated peptic ulcer. J Gastrointest Surg. 2011;15(8):1329-35.

5. Wroblewski LE, Peek RM, Wilson KT. Helicobacter pylori and gastric cancer: factors that modulate disease risk. Clin Microbiol Rev. 2010;23(4):713-39.

6. Humans IWGotEoCRt. Pharmaceuticals. Volume 100 A. A review of human carcinogens. IARC monographs on the evaluation of carcinogenic risks to humans. vol. 100, no. PT A, p. 1; 2012.

7. Maeda S, Mentis AF. Pathogenesis of Helicobacter pylori infection. Helicobacter. 2007;12(s1):10-4.

8. Mbulaiteye SM, Hisada M, El-Omar EM. Helicobacter pylori associated global gastric cancer burden. Front Biosci. 2009;14:1490.

9. Malfertheiner P, Megraud F, O'Morain CA, Gisbert JP, Kuipers EJ, Axon AT, et al. Management of Helicobacter pylori infection - the Maastricht V/ Florence consensus report. Gut. 2017;66(1):6-30.

10. Hooi JKY, Lai WY, Ng WK, Suen MMY, Underwood FE, Tanyingoh D, et al. Global prevalence of Helicobacter pylori infection: systematic review and meta-analysis. Gastroenterology. 2017;153(2):420-9. 
11. Hunt R, Xiao S, Megraud F, Leon-Barua R, Bazzoli F, Van der Merwe $S$, et al. Helicobacter pylori in developing countries. World gastroenterology organisation global guideline. J Gastrointest Liver Dis. 2011;20(3):299-304.

12. Walsh JH, Peterson WL. The treatment of Helicobacter pylori infection in the management of peptic ulcer disease. N Engl J Med. 1995;333(15):984-91.

13. Cheng H, Hu F, Zhang L, Yang G, Ma J, Hu J, et al. Prevalence of Helicobacter pylori infection and identification of risk factors in rural and urban Beijing, China. Helicobacter. 2009;14(2):128-33.

14. Bui D, Brown HE, Harris RB, Oren E. Serologic evidence for fecal-oral transmission of Helicobacter pylori. Am J Trop Med Hyg. 2016;94(1):82-8.

15. Parsonnet J, Shmuely H, Haggerty T. Fecal and oral shedding of Helicobacter pylori from healthy infected adults. JAMA. 1999;282(23):2240-5.

16. Enkhtungalag B, Batjargal J, Chimedsuren O, Tsogzolmaa B, Anderson CS, Webster J. Developing a national salt reduction strategy for Mongolia. Cardiovasc Diagn Ther. 2015;5(3):229.

17. Lundell LR, Dent J, Bennett JR, Blum AL, Armstrong D, Galmiche JP, et al. Endoscopic assessment of oesophagitis: clinical and functional correlates and further validation of the Los Angeles classification. Gut. 1999;45(2):172-80 (PubMed PMID: 10403727)

18. Kimura K, Takemoto T. An endoscopic recognition of the atrophic border and its significance in chronic gastritis. Endoscopy. 1969;1(03):87-97.

19. Dixon MF, Genta RM, Yardley JH, Correa P. Classification and grading of gastritis. The updated Sydney System. International Workshop on the Histopathology of Gastritis, Houston 1994. Am J Surg Pathol. 1996:20(10):1161-81.

20. Uchida T, Kanada R, Tsukamoto Y, Hijiya N, Matsuura K, Yano S, et al. Immunohistochemical diagnosis of the cagA-gene genotype of Helicobacter pylori with anti-East Asian CagA-specific antibody. Cancer Sci. 2007;98(4):521-8.

21. Correa P. Human gastric carcinogenesis: a multistep and multifactorial process - first American Cancer Society award lecture on cancer epidemiology and prevention. Cancer Res. 1992;52(24):6735-40.

22. Zhao D, Chen W, Yu T, He Y, Chen Z, Wen D, et al. A population-based matched case-control study on the risk factors of gastric cardia cancer. Zhonghua zhong liu za zhi [Chin J Oncol]. 2011;33(10):775-8.

23. Dixon MF IV. Helicobacter pylori and peptic ulceration: histopathological aspects. J Gastroenterol Hepatol. 1991;6(2):125-30.

24. Penston J. A decade of experience with long-term continuous treatment of peptic ulcers with $\mathrm{H} 2$-receptor antagonists. Aliment Pharmacol Ther. 1993;7(s2):27-33.

25. Correa P. Helicobacter pylori and gastric carcinogenesis. Am J Surg Pathol. 1995;19(Suppl 1):S37-43.

26. Choi IJ. Endoscopic gastric cancer screening and surveillance in high-risk groups. Clin Endosc. 2014;47(6):497-503

27. Uemura N, Okamoto S, Yamamoto S, Matsumura N, Yamaguchi S, Yamakido $\mathrm{M}$, et al. Helicobacter pylori infection and the development of gastric cancer. N Engl J Med. 2001;345(11):784-9.

28. Zhou Y, Li HY, Zhang JJ, Chen XY, Ge ZZ, Li XB. Operative link on gastritis assessment stage is an appropriate predictor of early gastric cancer. World J Gastroenterol. 2016;22(13):3670-8

29. Lee YY, Mahendra Raj S, Graham DY. Helicobacter pylori infection-a boon or a bane: lessons from studies in a low-prevalence population. Helicobacter. 2013;18(5):338-46.
30. Herrero R, Park JY, Forman D. The fight against gastric cancer-the IARC Working Group report. Best Pract Res Clin Gastroenterol. 2014;28(6):1107-14

31. Mera R, Fontham ET, Bravo LE, Bravo JC, Piazuelo MB, Camargo MC, et al. Long term follow up of patients treated for Helicobacter pylori infection. Gut. 2005;54(11):1536-40

32. Kosunen T, Aromaa A, Knekt P, Salomaa A, Rautelin H, Lohi P, et al. Helicobacter antibodies in 1973 and 1994 in the adult population of Vammala, Finland. Epidemiol Infect. 1997;119(1):29-34.

33. Brown LM. Helicobacter pylori: epidemiology and routes of transmission. Epidemiol Rev. 2000;22(2):283-97.

34. Song JH, Kim YS, Heo NJ, Lim JH, Yang SY, Chung GE, et al. High salt intake is associated with atrophic gastritis with intestinal metaplasia. Cancer Epidemiol Prev Biomark. 2017;26(7):1133-8.

35. Bergin IL, Sheppard BJ, Fox JG. Helicobacter pylori infection and high dietary salt independently induce atrophic gastritis and intestinal metaplasia in commercially available outbred Mongolian gerbils. Dig Dis Sci. 2003:48(3):475-85.

36. Sørbye H, Svanes C, Stangeland L, Kvinnsland S, Svanes K. Epithelial restitution and cellular proliferation after gastric mucosal damage caused by hypertonic $\mathrm{NaCl}$ in rats. Virchows Arch A. 1988;413(5):445-55.

37. Furihata C, Sato Y, Hosaka M, Matsushima T, Furukawa F, Takahashi M. $\mathrm{NaCl}$ induced ornithine decarboxylase and DNA synthesis in rat stomach mucosa. Biochem Biophys Res Commun. 1984;121(3):1027-32.

38. Ohgaki H, Szentirmay Z, Take M, Sugimura T. Effects of 4-week treatment with gastric carcinogens and enhancing agents on proliferation of gastric mucosa cells in rats. Cancer Lett. 1989:46(2):117-22.

39. Rojas-Campos N, Sigarán MF, Bravo AV, Jimenez-Ulate F, Correa P. Salt enhances the mutagenicity of nitrosated black beans. Nutr Cancer. 1990;14(1):1-3

40. Sørbye H, Kvinnsland S, Svanes K. Effect of salt-induced mucosal damage and healing on penetration of $N$-methyl- $N^{\prime}$-nitro- $N$-nitrosoguanidine to proliferative cells in the gastric mucosa of rats. Carcinogenesis. 1994;15(4):673-9.

41. Tsukamoto T, Toyoda T, Mizoshita T, Tatematsu M, editors. Helicobacter pylori infection and gastric carcinogenesis in rodent models. In: Seminars in immunopathology; 2013. Berlin: Springer.

42. Correa P, Piazuelo MB, Wilson KT. Pathology of gastric intestinal metaplasia: clinical implications. Am J Gastroenterol. 2010;105(3):493.

43. Nandurkar S, Talley NJ, Martin CJ, Ng TH, Adams S. Short segment Barrett's oesophagus: prevalence, diagnosis and associations. Gut. 1997:40(6):710-5.

44. Tang S, Wu R, Bhaijee F. Intestinal metaplasia of the stomach. Video J Encyclopedia GI Endosc. 2013;1(1):187-9.

45. Nilsson M, Johnsen R, Ye W, Hveem K, Lagergren J. Lifestyle related risk factors in the aetiology of gastro-oesophageal reflux. Gut. 2004;53(12):1730-5

46. Wu P, Zhao X-H, Ai Z-S, Sun H-H, Chen Y, Jiang Y-X, et al. Dietary intake and risk for reflux esophagitis: a case-control study. Gastroenterol Res Pract. 2013;2013(1):9

47. Backert S, Blaser MJ. The role of CagA in the gastric biology of Helicobacter pylori. Cancer Res. 2016;76(14):4028-31.

Ready to submit your research? Choose BMC and benefit from

- fast, convenient online submission

- thorough peer review by experienced researchers in your field

- rapid publication on acceptance

- support for research data, including large and complex data types

- gold Open Access which fosters wider collaboration and increased citations

- maximum visibility for your research: over 100M website views per year

At BMC, research is always in progress.

Learn more biomedcentral.com/submissions 